International Journal of Disability Management

http://journals.cambridge.org/IDM

Additional services for International Journal of Disability Management:

Email alerts: Click here

Subscriptions: Click here

Commercial reprints: Click here

Terms of use : $\underline{\text { Click here }}$

\title{
The Workers' Compensation Experience: A Qualitative Exploration of Workers' Beliefs Regarding the Impact of the Compensation System on Their Recovery and Rehabilitation
}

Cindy L. Wall, Shirley A. Morrissey and James R.P. Ogloff

International Journal of Disability Management / Volume 4 / Issue 02 / September 2009, pp 19 - 26

DOI: 10.1375/jdmr.4.2.19, Published online: 23 February 2012

Link to this article: http://journals.cambridge.org/abstract_S183385500000030X

How to cite this article:

Cindy L. Wall, Shirley A. Morrissey and James R.P. Ogloff (2009). The Workers' Compensation Experience: A Qualitative Exploration of Workers' Beliefs Regarding the Impact of the Compensation System on Their Recovery and Rehabilitation. International Journal of Disability Management, 4, pp 19-26 doi:10.1375/jdmr.4.2.19

Request Permissions : $\underline{\text { Click here }}$ 


\title{
The Workers' Compensation Experience: A Qualitative Exploration of Workers' Beliefs Regarding the Impact of the Compensation System on Their Recovery and Rehabilitation
}

\author{
Cindy L. Wall \\ Centre for Forensic Behavioural Science, Monash University, Australia \\ Shirley A. Morrissey \\ Griffith University, Australia \\ James R.P. Ogloff \\ Centre for Forensic Behavioural Science, Monash University, and Forensicare, Melbourne, Australia
}

\begin{abstract}
A tand ttempts to develop a better understanding of the interaction between the compensation environment and injured workers suggest that the compensation environment may negatively impact on the psychological wellbeing of injured workers. This study offers a complementary perspective to contemporary quantitative studies exploring the psychosocial aspects of workplace injury and disability, and contributes to the growing body of qualitative data on the interaction of personal and environmental factors influencing recovery from work injury. The beliefs and experience of injured workers, as explored through ethnographic interviewing, offer insight to the social meaning and relationships comprised in the compensation environment and reveal the pervasive impact of workplace injury across personal, social and occupational spheres. Poor claims administration and hostile interpersonal interactions are identified as particular sources of frustration and discontent for injured workers. Strong themes of perceived injustice emerge as a potentially valuable area for future research in improving the outcomes of compensable injury.
\end{abstract}

Keywords: occupational health, workplace, rehabilitation, health experiences, psychosocial aspects

The loss of work opportunities through illness and injury represents serious threats to mental and physical wellbeing. In recognition of the many negative effects of work injury and disability, researchers have attempted to identify psychosocial factors critical to prolonged claims and work disability. Despite abundant research and intervention from clinical, health, and organisational psychology perspectives, workplace injury and disability rates are not decreasing. Contemporary quantitative investigations are now focused on exploring the potential interactions between sets of individual and environmental factors identified in earlier studies to more fully understand the complexity of workplace injury. Qualitative studies have tended to be less prominent and less influential with respect to policy decisions and rehabilitation planning. However, consistent themes related to the work injury experience are being revealed from studies using qualitative approaches. As a result, attention is being directed toward more detailed exploration of injured workers' beliefs and perceptions

Address for correspondence: Cindy Wall, GPO Box 107, Darwin NT 0801,Australia. E-mail: cindy.wall@wisemind.com.au

Wall, C.L., Morrissey, S.A., \& Ogloff, J.R.P. (2009). The workers' compensation experience: A qualitative exploration of workers' beliefs regarding the impact of the compensation system on their recovery and rehabilitation. International Journal of Disability Management Research, 4(2), 19-26. 
of the compensation process as potential influencing factors on recovery and return to work.

Workers who sustain injuries and are compensated under a workers compensation system should enjoy timely and efficient health care and administrative assistance to facilitate effective rehabilitation and return to work. While this is good in theory, it certainly is not always the case in practice. A comparative analysis of research indicates that when compared to nonclaimants with similar injuries, workers with compensable injuries experience longer recovery periods (Curtin University School of Occupational Therapy, 2001), possess elevated levels of psychological pathology (Mason \& Turpin, 2002), and are at risk of developing ongoing work disability (Wall, Ogloff, \& Morrissey, 2007), irrespective of geographical location or injury type. A number of psychosocial factors have been implicated in contributing to the recovery of injured workers from empirical studies (Waddell, 2004), yet a consistent set of factors is yet to emerge. This discrepancy has heightened consideration of the role of workers' beliefs and expectations in regard to coping with compensable injury, with studies suggesting that such beliefs may be instrumental in facilitating adaptive coping and return to work (Cole, Mondloch, \& Hogg-Johnson, 2002; Heymans et al., 2006; Strunin \& Boden, 2004). This article reports on findings from interview data exploring injured workers experiences and beliefs regarding their interaction with a workers compensation system and associated stakeholders, as potential contributors to recovery from compensable injury.

\section{The Workers Compensation Environment}

Workers compensation systems are designed to help injured workers to recover payments from employers to alleviate the consequences of injuries sustained during the course of their work. Specifically, an injured worker is provided with income support and coverage for health care expenses resulting from the work-related injury, and may be provided with vocational rehabilitation assistance as a component of facilitating return to work. Entitlements for workers' compensation coverage vary among jurisdictions; however, a set of universal concerns relating to the economic, social, and the human cost of workers' compensation has been identified. These concerns specifically relate to the continuing escalation of costs associated with work injury and disability, despite a groundswell of research activity, increasing adoption of a biopsychosocial approach to rehabilitation (Sullivan, Feuerstein, Gatchel, Linton, \& Pransky, 2005), the development of structured psychosocial intervention programs (Pransky, Gatchel, Linton, \& Loisel, 2005) and evidence-based practice (Murphy, King, \& Ollendick, 2007).

\section{Workers Compensation in Australia}

In Australia, workers' compensation is legislated by relevant governing bodies at State, Territory and Commonwealth levels. This legislative framework for occupational health and safety, compensation, and rehabilitation of an injured worker in the Northern Territory is provided by the Northern Territory Government's Work Health Act (2006). The Northern Territory does not require the establishment of 'fault' to access compensation - but does require that workplace injury, illness, or fatality, occurred in the course of employment. Such statutory schemes tend to have a benefit structure that meets the ongoing needs of seriously or permanently impaired workers. In jurisdictions where access to common law is available, the statutory workers compensation schemes tend to differ from that in the Northern Territory in that they are structured toward workers with shortterm illnesses or injury. This enables common law action to address the needs of more seriously injured workers.

Income support for an injured worker in the Northern Territory is equal to the difference between current weekly earnings and the worker's usual preinjury weekly earnings, up to $100 \%$ of weekly preinjury earnings for the first 26 weeks of a claim. Should a worker remain incapacitated beyond this period, then income support is reduced to $75 \%$ of the worker's loss of earning capacity. These benefits may continue until the injured worker returns to work at a salary level that is at least equivalent to pre-injury earnings, or reaches age 65 years; or reaches the usual retirement age for that industry if it is greater than age 65 ; or finally when there is a proven 'ceasing of liability' (Northern Territory Government, 2006). Despite there being the possibility of injured workers receiving compensation for very long periods of time, an independent evaluation of the workers compensation system in the Northern Territory found that injured workers in the Territory were returning to work on average 25 days faster, and spending considerably less time in receipt of compensation when compared to other jurisdictions (Titto, 1998). This report is more than a decade old, and attributed these positive outcomes to a focus on early intervention and return to work. More recent comparable statistics are not available; however, anecdotal information suggests that these benefits have not been maintained, and that there has been an increase in recent times of dissatisfaction with the system, and longer periods out of work for work-injured claimants.

This picture is consistent with reports from other jurisdictions both locally and internationally. Review of extant literature regarding workers compensation and recovery from compensable injury by the Western Australian Rehabilitation Commission identified that injured workers engaged in compensation consumed greater medical and rehabilitation services, and had higher costs than their non-compensable peers (Curtin 
University School of Occupational Therapy, 2001). It was also found that factors such as inadequate early diagnosis and treatment, communication breakdown, and negative stereotyping of claimants contributed to the slower recovery rates evident in this population. Importantly, contextual or system factors within the compensation system are now attracting more serious consideration as potential impediments to an injured worker's recovery. Factors such as worker-employer relationship, the socioeconomic environment, worker expectations (e.g., role clarity), administrative concerns (e.g., paperwork) and poor communication between stakeholders, are touted as providing clues to the disparity between the medical diagnosis and reported disability in this population.

\section{The Association between Worker Beliefs and Recovery}

A disparity exists between the relatively lower levels of severity of workplace injuries compared with nonworkplace injuries (Mason \& Turpin, 2002) and the high human and financial costs associated with the growing rates of work disability. The identification of specific interactions between injured workers, their beliefs, perceptions, and recovery within the context of compensable injury are emerging as valuable sources of information from which to construct improved claims management and rehabilitation processes. A prospective study exploring recovery expectations in the prediction of outcomes in return to work, found that injured workers with more positive expectations spent less time away from work and were less likely to be in receipt of compensation than those with more negative expectations (Cole et al., 2002). Self-predicted timing of return to work, job satisfaction, and treatment expectations of injured workers have been found to affect return to work following sick leave (Heymans et al., 2006). Common to these findings is the sense of inclusion and a degree of influence on the part of the injured worker to affect their own rehabilitation and return to work. In general the literature on the expectations of workers with respect to treatment success and returning to the workplace point toward workers' beliefs and perceptions as being useful prognostic indicators of work absence and rehabilitation from compensable injury (Reiso et al., 2003; Schultz et al., 2004).

\section{The Importance of Perceived Control}

Perceived control is emerging as central factor in the rehabilitation of injured workers. Early studies suggest that injured workers with an internal locus of control progress more quickly through rehabilitation (Norman \& Normal, 1991), and have shorter recovery periods (Partridge \& Johnston, 1989), than their externally-oriented peers. A relatively recent investigation into the relationship between locus of control and vocational rehabilitation offered further support for this relationship, identifying a positive association between internal locus of control and rehabilitation outcomes (Millet \& Sandberg, 2003).

\section{Self-Identity, Compensation, and Wellness}

Workers beliefs, expectations, and values are intrinsically associated with self-identity. When deprived of the opportunity to engage in meaningful work, individuals experience decreased wellbeing and eroded identity (Cacciacarro \& Krish, 2006). Individual descriptions of the experience of workplace injury and subsequent interactions with stakeholders reported in qualitative investigations conducted by Stone (2003) and Cacciacarro and Kirsh (2006) provide illustrations of the power of these interpersonal interactions. In these studies injured workers reported that workplace injury was the most physically and psychologically devastating event to occur within the context of their lives. They described drastic changes to home and family life, feelings of social alienation, helplessness, and a constant need to prove legitimacy. Cumulative erosion of self-identity associated with ongoing negative interactions with workers compensation authorities, the impact of the stigma of being work-injured on social and co-worker relationships (Svensson, Karlsson, Alexanderson, \& Nordqvist, 2003), and reduced self-efficacy, feature heavily in the compensation experience and are frequently reported in the context of poor outcomes.

\section{An Evolving Adversarial Climate}

A large percentage of injured workers reported being frustrated and demeaned by their interactions with the compensation system resulting in short- and longterm negative consequences (Strunin \& Boden, 2004). The perception of being treated with suspicion and disbelief by insurance authorities is prominent in the accounts of work-injured individuals (Svensson et al., 2003). When combined with administrative issues such as delays in payments, unexpected termination of benefits, and receiving too little or far too much information about entitlements, these factors contribute to an adversarial climate culminating in the worker having little understanding of the system and feeling not in control of the situation (Strunin \& Boden, 2004). In light of such research it has been argued that the worker's relationship with the compensation system is a major barrier to the injured worker's mental health (Cacciacarro \& Krish, 2006).

\section{Study Overview}

The current study explored injured workers' experiences of engaging with the Northern Territory workers compensation system following workplace injury, and their beliefs regarding the impact of this interaction on their recovery and rehabilitation. As stated, the Northern Territory's workers compensation system differs from those operating in other Australian 
jurisdictions in that it is primarily a pension-based scheme without access to common law. The Northern Territory compensation and rehabilitation systems were independently assessed as demonstrating bestpractice rehabilitation and return-to-work outcomes a decade ago (Titto, 1998); however, there has been anecdotal evidence that this achievement has not been sustained. It is envisaged that increased understanding of the subjective experience of work-injured claimants, and identification of consistent thematic factors may positively complement and inform quantitative investigations in this area. This information may improve injury management policy and practices, facilitating investment in processes that are generated from a bottom-up rather than top-down philosophy.

\section{Materials and Method}

\section{Sample Selection and Procedure}

Ethnographic open-ended interviews were conducted with 36 (18 male, 18 female) injured workers with compensable injuries recruited through Northern Territory vocational rehabilitation agencies. Interviews were conducted between 2003 and 2005. Ethnographic approaches to data collection enable the production of qualitative data rich in detail, due to the careful description of person environment interactions, and attention to the direct quoting of the participant's subjective account. Ethnographic interviewing relates to the anthropological method of describing the local point of view, yielding a study of systems of meaning and rules (Hahn, 1995). This approach permits an understanding of the world, seen through the eyes of the respondent, within the context of their daily life (Strunin \& Boden, 2000).

All workers participating in the study had a recognisable claim for workers compensation in the Northern Territory in the preceding 5 years, and had participated in at least one vocational rehabilitation program within the preceding 24 months, with an average duration of 17 weeks. Worker injury type included psychological and physical injuries, excluding head injury. The age of participants ranged from 24 to 63 years, with an average age of 49 years. Participants were found to be representative of Northern Territory workers compensation claimants who had taken part in vocational rehabilitation when compared on demographic and injury variables with 125 client vocational rehabilitation files closed in 2002. This comparison was conducted to ascertain sample representativeness given the voluntary nature of participation and the relatively small number of interviewees.

Interviews were recorded verbatim, with coded subject numbers recorded in lieu of participant names. Interviews varied between 45 and 90 minutes in length. There were no incentives offered for injured workers to take part in the research. The study was approved by the Charles Darwin University and Monash University Ethics Committees.

\section{Interview Design}

A semi-structured interview guide was adopted to assist in the collection of comparable data, listing topics and questions in a set order. Participants were asked to describe their work injury experience, indicate their level satisfaction with the insurer and rehabilitation provider, and to comment on the impact of being involved in the compensation system on their self-identity. They were also asked to identify the useful aspects of the system and any changes they would like to see made as a result of their experience. Finally, participants were asked to consider that if their injury had been non-compensable, what would have been different. All interviews were conducted by the same investigator, a clinical psychologist with expertise in the psychological aspects of workplace injury.

\section{Analytical Procedures}

Responses were coded by the interviewing investigator. In the coding process themes were identified in the text and given a theme label. As the interviews were based on a semi-structured format, participants already had a series of mutually relevant topics around which to structure their responses (i.e., satisfaction with insurer and rehabilitation provider; impact of compensation; useful aspects of the NT system; changes required, and possible differences had the injury been non-compensable). The results were initially grouped around these categories. Multiple readings of the transcripts, and more detailed analysis and interpretation of the categories resulted in the extraction of common themes and the notation of differences. The themes that emerged around those categories are presented in the following section. A selection of direct quotations from each category is provided to illustrate the dominant themes offered by participants. An independent co-rater read all the transcripts and data matrices to ensure the validity of the themes extracted. Any discrepancies were discussed and agreement was reached in regard to all the major themes identified.

\section{Results}

Results suggest that a large number of injured workers experience the compensation and rehabilitation systems as disempowering, frustrating, and distressing. Negative themes related to self-identity, responsibility, justice and fairness, stigma, mistrust, and lack of perceived support were apparent. Workers' beliefs and expectations framed their work-injury experience, resulting in some common themes emerging from their interpretations despite strikingly dissimilar injuries and work situations. These themes are described in the following paragraphs, grouped around the semi-structured interview topics from which they were evoked. These include overall work injury and compensation experience, followed by satisfaction with insurer and rehabilitation provider, impact on 
self-identity, the usefulness of the system and identification of any changes required, and finally reflections on what would be different if the injury had been non-compensable.

\section{The Work Injury Experience}

Workers in the study reported a range of experiences associated with their work injury which appeared to relate to locus of control. Some reported assuming responsibility for their injury management irrespective of what they were or were not entitled to under compensation. It appeared that these individuals possessed a more internal locus of control as reflected in the following two examples:

I took charge myself and liaised with the insurer directly. I chose to stay as physically active as possible while waiting for surgery, which was delayed. I returned to work immediately following surgery and maintained a fitness program with minimal input from a physiotherapist. My main incentive was to resume my normal lifestyle which had been restricted due to the physical limitations of my injury. (Male, public servant, shoulder injury)

I was on limited duties as I was in plaster and unable to drive due to pain. At this time, no rehabilitation provider or support agency communicated with me or gave any input. I wasn't aware that this was supposed to occur. I handled all the paperwork and contact with the insurer myself. They took their time approving the initial surgery — but it went through. I then organized my own return to work and limitations related to my injury. (Female, teacher, arm injury)

Some who took a proactive stance reported annoyance that the system did not assume the required responsibility for their care and injury management; however, most adopting this approach reported good recovery and return to work outcome. Protracted and distressing work injury experiences were characterised by themes of helplessness, confusion, and suspicion, which may reflect a more externalised locus of control. Workers with these beliefs tended to report negative reactions when dealing with the demands of the compensation system as well as negative interactions with its representatives, as illustrated in the following two accounts:

The whole process failed. It's all cloak and dagger stuff each person would only give you a small piece of information. Then you were pushed to get back to work. (Male, tradesman, back injury)

It was a shock. The whole process was very impersonal with lots of assessments. (Female, administrative worker, psychological injury)

The social and personal impacts of work injury were prominent in the work injury experience. Many participants reported being unprepared for changes that occurred in their relationships with family and friends once their injury did not resolve quickly. Frustration and depression were commonly reported. The following accounts give some indication of the typical level of disruption to family and co-worker relations reported:

The physical impingement was bad enough. However during this four-month period there was a major change in my relationship with staff at my workplace. They stopped engaging with me; didn't request my input; didn't make me welcome in their class. The principal was especially antagonistic and accused me of parading my pain in front of another individual who had been involved in my workplace accident. Members of staff began bypassing me in the community. I don't know what was said or inferred, I only know that everything changed and people I had trusted, socialised with and interacted with professionally, treated my like a pariah. I was an emotional wreck. (Female, teacher, arm injury)

Many of my workmates were insensitive to my condition. I constantly had to explain to friends, family, acquaintances that I was still on the job, and that I was injured, only to be told that I didn't look injured. I slept extremely poorly, communicated in a terrible manner to my family, and was irritable and inconsolable on many occasions. I felt abandoned. My reactions covered a range of emotions from suicidal ideation to a terrible consuming anger at myself, my family, and the job. (Male, law enforcement, psychological injury)

My life will never be the same. I am not the same person. I am no longer outgoing. I can't think straight. I have difficulty even going to the shopping centre, I have been suicidal. (Female, nurse, traumatic stress)

\section{Satisfaction With Insurer and Rehabilitation Provider}

Injured workers' levels of satisfaction with the insurer and rehabilitation provider tended to be polarised despite progressing through the same legislative process. Perceived satisfaction appeared highly dependent on the quality of interactions with a particular claims officer or rehabilitation consultant, and the level of attention paid to timely execution of administrative tasks associated with the claim. This was clearly illustrated in situations where the worker had been involved with more than one representative from the same organization - giving each a dramatically different satisfaction rating. Interestingly, rarely did a participant report consistently high or low satisfaction with all parties involved in his or her injury management. Generally, it seemed that interactions with the rehabilitation provider were pivotal in influencing satisfaction. The following three accounts demonstrate this variability.

The insurer was very proactive and made things happen quickly - they facilitated the entire bill-paying so I could just get better. (Male, technician, shoulder injury)

The rehabilitation provider was highly ineffectual and merely buried everything in paperwork. The insurer was recalcitrant as always. None of the agency professionals offered assistance or advocacy in gaining reimbursements or making provisions for health care. (Female, teacher, knee injury) 
The rehabilitation lady was very abrupt; she didn't want to hear my side of the story. She made me feel worse than I already did - it was very disappointing. (Female, administration worker, psychological injury)

\section{Impact on Self-Identity}

Injured workers describing negative compensation experiences reported greater impact on self-identity, particularly in regard to increased cynicism and reduced trust in themselves, others, and 'the system'.

I have not handled the situation well at all. Nearly four years down the track I have come to realise that I am as affected now as I was when I first lodged the claim. Many times I wish I never had. My personal life has deteriorated and I have uncontrollable episodes of anger. I believe that I have always suffered from low self-esteem and there is no doubt in my mind that this has gotten progressively worse over the last four years. (Male, law enforcement, psychological injury)

I am no longer in control of my own life. I am always looking for a double meaning. This experience destroys trust and makes you feel useless. (Female, nurse, back injury)

I am far less trusting and more fragile than before. I have less self-confidence and doubt my competence. It is hard to cope with certain people in the workplace now. (Female, financial planner, psychological injury)

The majority of responses to the question of changes to self-identity described an eroded sense of self-confidence and reduced trust in others. Many reported disturbed affect - more likely to represent affective state, rather than personality trait changes, which spilled over into their social and personal relationships. There was a strong theme of social disconnection and alienation, which appeared to either elicit sadness or anger.

\section{The Northern Territory Compensation System: Retention and Change}

Injured workers' comments regarding the useful aspects of the NT system and suggestions for change were dominated by perceptions of unfairness or injustice. Consistent with earlier research, areas requiring attention were identified as - administrative procedure and interpersonal interactions. Financial provisions for health care (when received in a timely fashion) were perceived to reduce stress and validate the injured worker. However, when the administration process is delayed or disrupted, workers generally reported mistrust and invalidation. Interpersonal interactions with stakeholders were reported as having a powerful influence on injured workers perceptions of the system, themselves, and on their subsequent behavior. Those who reported feeling particularly dismissed were less likely to engage in rehabilitation and more likely to consider litigation, the following extracts illustrates these differing perceptions.

It was useful to have all the financials taken care of, and to have access to specialists who knew what they were doing. It would be better if there was a more open assessment at the start of the claim - I thought I would be back at work straight away and was not prepared for the delay or the return to work process. (Female, teacher, foot injury)

The whole system needs an overhaul. It took seven weeks to lodge paperwork, I was injured and still trying to work while in pain. I couldn't afford to stop. The whole system let me down - I just wanted what I was entitled to and told them (insurer). They said I needed anger management. (Male, truck driver, back injury)

It was useful not to have to worry about income - it gave me peace of mind, as well as an opportunity to get back on my feet (Male, sales, knee injury)

The access to rehab was excellent but the insurer needs to change the way they deal with people. The case managers were disrespectful and condescending - they need to change their attitude and treat you like an individual. (Female, counselor, back injury)

Recognition of the financial support for healthcare treatment was widespread, although apart from that there was an absence of other aspects of the systems that participants suggested retaining. In comparison The Northern Territory's practice of employing a step-down benefit structure which reduces compensations benefits by $25 \%$ at week 26 of the claim was raised by many participants as sending a negative message to the injured worker, and was largely perceived as unfair. Many took personal offence to this part of the legislation, some described a belief that it was a type of punishment for being injured; others perceived that it was the insurer's way of suggesting that the worker was a malingerer.

The system was not useful at all. It needs changing. Insurers need to treat you like an individual. The drop to $75 \%$ after 6 months is not fair and doesn't make sense. A new and fairer assessment criterion is needed. (Female, flight nurse, back injury)

The system is less than satisfactory. I found the only certainty about the process was that it was disjointed, overly bureaucratic and not health oriented in any way, shape, or form. Clearly it was about the quickest and cheapest way of effecting, what, in my opinion, passes for rehabilitation under the present scheme. The situation where someone can be work disabled and then only receive $75 \%$ is un-Australian. It is simply unfair and should be remedied by government action. (Male, law enforcement, psychological injury)

Although all jurisdictions have some form of stepdown or capped benefits even injured workers who reported positive experiences in the compensation system had difficulty understanding the rationale for the drop in benefit. This important aspect of injured workers' entitlements appeared to have been poorly explained or retained by injured workers and was a source of distress and frustration.

\section{If This Injury Was Non-Compensable, How Would Things Be Different?}

Respondents were asked to reflect hypothetically on how the compensable status of their injury affected 
recovery and return to work. Workers were almost unanimous in expressing difficulty or inability to meet the financial burden they would have had to bear had their injury been non-compensable. Those who reported positive interactions with the insurer were appreciative of not having the added concern of worrying about lost income while incapacitated.

If I could not access compensation I would have done more damage as I would have had to continue to work. (Male, manual work, back injury)

Without compensation I would have had to try to return to work earlier, I would not have been able to pay for the interventions. (Female, teacher, foot injury)

Some, however, felt that in spite of the financial relief of compensation, they would have avoided considerable psychological and emotional distress by not engaging in the compensation and rehabilitation systems, as reflected in the comments below.

In hindsight I would have been better managing my injury through my private health insurance. (Female, nurse, back injury)

If this were not compensable I would be injured but I would have not become an invalid. (Female, counselor, back injury)

\section{Discussion}

The beliefs and perceptions of injured workers with compensable injuries in regards to fair and equitable treatment, access to services and information, frank and inclusive decision-making and return to work planning appeared to be important determinants in facilitating effective injury management. Similar to earlier research, injured workers who perceived greater control and inclusion in the process reported greater satisfaction and less residual negativity than those perceiving less control and greater alienation. Importantly, the perception that insurers, medical professionals, rehabilitation consultants, employers, workmates, family and friends, viewed participants injuries as genuine and appreciated their attempts to recover and return to work, seemed to represent the lens through which the compensation experience was viewed.

Those in the study reporting negative compensation and rehabilitation experiences described common perceptions of mistrust and injustice, inadequate administrative support, and interactions with stakeholders that were demeaning and stigmatising. These findings were consistent with themes identified by Strunin and Boden (2004) who argue that workers invariably experience the compensation system as highly stressful; however, it is noteworthy that, in the current study the theme of perceived injustice especially with respect to procedural violations and/or unfairness - was particularly dominant in a majority of responses.
Perceptions of injustice and unfairness were raised in relation to the process of administering the claim, the legislative framework, and in regard to insurer, rehabilitation provider, and employer behaviour. Although such beliefs have been identified elsewhere in the literature (Strunin \& Boden, 2004; Svensson et al., 2003), the pervasiveness of perceived injustice identified even by those who reported positive compensation experiences suggest that this may be a pivotal factor in workplace rehabilitation. For example, it is apparent that administrative processes influence worker identity and self-worth, as in cases where benefits were delayed, paperwork lost, or claims officers and case mangers changed without notice, workers experienced invalidation and frustration. Importantly, where these administrative issues were perceived as sources of unfairness and injustice an adversarial climate was also reported.

The pressure on workers to be seen as 'compliant' with the rules of compensation or risk cessation of benefit, was viewed as inequitable in the light of insurer delays in travel or fuel reimbursements, surgery, and assessment notifications. These perceptions of injustice appeared to motivate retribution via reduced flexibility, compliance, and even litigation on the part of the injured worker. The most strikingly consistent source of perceived injustice reported in this study related to the legislated step-down in benefit payments at 26 weeks post injury. Injured workers attempting to recover perceived this as a punishment which implied potential malingering.

The power of interpersonal interactions with stakeholders (and the subsequent behaviors of these stakeholders) to influence perceptions of justice and fairness was evident from the participant responses. It would seem that the perception of an empathic and attentive claims officer or rehabilitation consultant considerably enhanced workers sense of identity and sense of support. Without having to worry about consistently proving entitlement to benefits, such workers reported a smoother transition back into the workplace. In contrast, a claims officer or rehabilitation consultant who was perceived as suspicious or hostile, who conveyed the sense that the claim was not genuine, not only challenged workers' identities, but amplified beliefs of unfairness and injustice. Some workers described such interactions as the impetus for exploring options for litigation, where the motivation was one of principle rather than monetary.

The prominence of perceived injustice conveyed in the accounts of participants irrespective of their injury, level of satisfaction, or outcome is noteworthy. The consistency with which perceived injustice was reported to have been a contributing factor toward an evolving adversarial climate, and/or litigation is also interesting. Future research, both qualitative and quantitative, may find justice beliefs in regard to compensable injury a rich area of theoretical and practical significance. 
This qualitative exploration of the compensation experiences of 36 injured workers in the Northern Territory does not provide evidence of causality or statistically significant relationships. Furthermore, in adopting an ethnographic approach, the responses from participants may reflect bias from potential over or underestimation of difficulties associated with various interpersonal interactions, inaccurate recall, or individual differences such as personality, mood or affective disorders. However, this approach does offer an insight to the social meaning and relationships comprised in the compensation environment as seen through the eyes of these injured workers, highlighting the pervasive impact of workplace injury across personal, social and occupational spheres.

The findings identify similar themes to previous qualitative investigations, allowing injured workers to present their perceptions, beliefs, and issues of concern to them. The two consistent themes related to timely administration of claims, and the style and tone of interpersonal interactions between injured workers and those involved in managing their claim, have immediate applied relevance for improved compensable injury management via the education and training of insurance and injury management personnel. Injured workers expected fair and just treatment, and sought retribution for perceived injustices - in both administrative and interpersonal aspects of their injury management.

The breadth of experiences and perceptions reported by individuals proceeding through the same legislative framework suggests the possibility that workers interpret the compensation environment through a set of beliefs and values which may not be in sync with the legislative framework, and thereby contribute to the evolution of an adversarial climate that amplifies psychological distress and protracts recovery. Future research exploring these specific belief and value sets may be instrumental in improving the way in which rehabilitation from workplace injury is operationalised in the future. From the themes emergent from this study further investigation of the role of justice sensitivity in rehabilitation from compensable injury for injured workers is indicated.

\section{References}

Cacciacarro, L., \& Krish, B. (2006). Exploring the mental health needs of injured workers. The Canadian Journal of Occupational Therapy, 73(3), 178-187.

Cole, D.C., Mondloch, M.V., \& Hogg-Johnson, S. (2002). Listening to injured workers: How recovery expectations, predict outcomes - a prospective study. Canadian Medical Association Journal, 166(6), 749-754.

Curtin University School of Occupational Therapy. (2001). Does workers' compensation influence recovery rates? Perth, Western Australia: Author.
Hahn, R.A. (1995). Sickness and healing. New Haven, CT: Yale University Press.

Heymans, M.W., de Vet, H.C., Knol, D.L., Bongers, P.M., Koes, B.W., \& van Mechelen, W. (2006). Workers' beliefs and expectations after return to work over 12 months. Journal of Occupational Rehabilitation, 16, 685-695.

Mason, S., \& Turpin, G. (2002). Outcomes after injury: A comparison of workplace and non-workplace injury. Journal of Trauma, Injury, Infection, and Critical Care, 53(1), 98-103.

Millet, P., \& Sandberg, K.W. (2003). Locus of control and its relationship with vocational rehabilitation of unemployed sick leaves in Sweden. Journal of Vocational Rehabilitation, 19, 59-66.

Murphy, G.C., King, N.J., \& Ollendick, T.H. (2007). Identifying and developing effective interventions in rehabilitation settings: Recognizing the limits of the evidence-based practice approach. Australian Journal of Rehabilitation Counseling, 13(1), 14-19.

Norman, E. J., \& Normal, I. V. (1991). Relationship of patients? Health locus of control beliefs to progress in rehabilitation. Journal of Rehabilitation, Jan/Feb/March, 27-30.

Northern Territory Government. (2006). Work Health Act. Darwin: Author.

Partridge, C., \& Johnston, M. (1989). Perceived control of recovery from physical disability: Measurement and prediction. British Journal of Clinical Psychology, 28, 53-60.

Pransky, G., Gatchel, R., Linton, S.J., \& Loisel, P. (2005). Improving return to work research. Journal of Occupational Rehabilitation, 15(4), 453-458

Reiso, H., Nygard, J., Jorgensen, G., Holanger, R., Soldal, D., \& Bruusgaard, D. (2003). Back to work: Predictors of return to work among patients with back disorders certified as sick: A two-year follow-up study. Spine, 28, 1468-1473.

Schultz, I. Z., Crook, J., Meloche, G.R., Berkowitz, J., Milner, R., Zuberbier, O.A., et al. (2004). Psychosocial factors predictive of occupational low back disability: Towards development of a return-to-work model. Pain, 107, 77-85.

Strunin, L., \& Boden, L.I. (2000). Paths of reentry: Employment experiences of injured workers. American Journal of Industrial Medicine, 38, 373-384.

Strunin, L., \& Boden, L.I. (2004). The workers' compensation system: Worker friend or foe? American Journal of Industrial Medicine, 45, 338-345.

Sullivan, M.J., Feuerstein, M., Gatchel, R., Linton, S.J., \& Pransky, G. (2005). Integrating psychosocial and behavioural interventions to achieve optimal rehabilitation outcomes. Journal of Occupational Rehabilitation, 15(4), 475-389.

Svensson, T., Karlsson, A., Alexanderson, K., \& Nordqvist, C. (2003). Shame-inducing encounters. Negative emotional aspects of sickness-absentee's interactions with rehabilitation professional. Journal of Occupational Rehabilitation, 13(3), 183-195.

Titto, F. (1998). Getting back to work: Final report of the evaluation of rehabilitation in the Northern Territory work health system. Darwin: Enduring Solutions PL.

Waddell, G. (2004). The back pain revolution. London: Churchill Livingstone.

Wall, C.L., Ogloff, J.R.P., \& Morrissey, S.A. (2007). Psychological consequences of work injury: Personality, trauma and psychological distress symptoms of non-injured workers and injured workers returning to, or remaining at work. International Journal of Disability Management Research, 2, 37-46. 